\title{
Strategies for the Adoption of E-commerce
}

\section{José G Vargas-Hernández*}

Department of Economics, University Center for Economic and Managerial Sciences, University of Guadalajara, México

\begin{abstract}
This work seeks to analyze if there is an impact from the adoption of technology used for online transactions, starting from the theories of adoption of electronic commerce as well as the strategies that companies choose to develop a competitive advantage, the models on economic interactions, the barriers on the part of companies to be included in the electronic marketplace, Mexico data are revised in recent years to review the trend that has been e-commerce and exploratory.
\end{abstract}

Keywords: Adoption; E-commerce; Strategies

\section{Introduction}

E-commerce transactions are digital channels, which in many cases include data exchange for transactions between businesses and/ or consumers. Within the e-commerce there are different types of models which are named according to the actors involved in them, either consumers, corporations or government, should be analyzed that although the relationship between companies is showing increased volume of trade is very interesting to review the models formed from these relationships. To see how e-commerce behaves in Mexico is attractive because it has only begun to take important and forecast to grow in the coming years.

This paper rises to be explanatory as to the theories that analyze e-commerce such as those based on the industry and also centered on the resources and capabilities. The first approach is based on the model of Porter and strategies that are given in the e-commerce adoption, to review the behavior of Mexico in e-commerce measured by Internet users viewed as potential customers and online sales reflecting market size and economic impact of e-commerce in these moments [1].

\section{Problem Delimitation}

While some authors note that electronic commerce provides benefits to firms, but Mata, Fuerst and Barney argue that although the literature agrees that IT resources alone do not produce competitive advantage, produce business value when combined and coordinated with other organizational and environmental resources [2]. Retailers are facing a kind of increasingly demanding and better formed that access to consumer brand from different channels, from waiting for a completely homogeneous purchase experience: speed, convenience and customization are undoubtedly attributes expected by consumers in these interactions with the brand. It is to analyze whether to adopt e-commerce is an advantage.

\section{Theoretical Framework}

Alongside the institutional theory, Tornatzky and Fleischer discuss the framework TOE which is one of the theories that guide most frequently used in the investigation of technology adoption [3]. It identifies three types of factors that affect the adoption of technology innovation: technological context organizational context, for example, the size, the complexity of management structures, communication processes, the availability of slack resources, and context the environment, e.g., industry characteristics and market structure, IT infrastructure, government regulation). All these are under TOE because it is a well-defined framework. It is also consistent with the theory of diffusion of innovations [4].
Institutional theory suggests that organizations face pressures to conform widely to the practices and policies that are considered legitimate in their institutional settings. In the work of DiMaggio and Powell, to do so may deny them the resources and social support to be competitive [5]. The TOE framework is used to study the diffusion of innovations of various system information, including technical tasks, supporting business administration and information system innovations integrated into the core business [6]. Internal technological resources such as infrastructure, expertise, time developer and user are significant for success is the adoption [7].

There is evidence in the literature that various technological, organizational and environmental factors distinguish adopters of e-commerce for non-adopters and influence the extent to which firms adopt these technologies. Some firms are unwilling to commit the resources to participate in online markets, while others devote their resources to establish the necessary processes to participate in the online business, according to Grewal, Comer and Metha [8]. A theory that has been widely used in the adoption of innovation and the adoption of e-commerce literature is the resource-based theory [9] tells that the resource-based theory argues that firms are heterogeneous resources that enable them to achieve a competitive advantage and superior long-term performance.

In an important context for companies to prepare their strategies and practices to adapt to different cultures, legal frameworks, geographic regions and industry structures context. However, research often focuses on "general theories" and puts relatively little attention to the boundary conditions, and to direct and moderate the influence of contextual variables [10].

\section{E-commerce}

Some authors like Laudon and Traver, and Owens define electronic commerce such as transactions and activities that occur in the WEB $[11,12]$. More formally, digitally enabled commercial transactions

*Corresponding author: José G Vargas-Hernández, Department of Economics, University Center for Economic and Managerial Sciences, University of Guadalajara, México, Tel: +523337703340; E mail: josevargas@cucea.udg.mx

Received June 26, 2015; Accepted October 23, 2015; Published October 26 , 2015

Citation: Vargas-Hernández JG (2015) Strategies for the Adoption of E-commerce. J Glob Econ 3: 157. doi:10.4172/2375-4389.1000157

Copyright: (c) 2015 Vargas-Hernández JG. This is an open-access article distributed under the terms of the Creative Commons Attribution License, which permits unrestricted use, distribution, and reproduction in any medium, provided the original author and source are credited. 
between two or more organizations and individuals. Commercial transactions involve the exchange of value across organizational or individual borders in exchange for goods and services. Exchange value is important for understanding the limits of e-commerce as Figueroa, Hernandez, Gonzalez and Arrieta [13].

E-commerce allows to understand how companies have developed in recent years and the adoption of electronic commerce to their procedures have grown significantly to improve their conditions regarding presence in the international market and break down barriers and reduce costs by removing intermediaries in the value chain. The literature on electronic commerce reveals that the adoption of electronic commerce potentially brings significant benefits to SMEs as support [14].

The composition of electronic commerce has remained fairly constant over the past 10 years. E-commerce is dominated by businessto-business (B2B) sales which are often handled through electronic data interchange (EDI). Approximately $90 \%$ of the value of e-commerce is B2B. Social networks and participatory web are also used increasingly to market and sell products online in a way that is best suited to individual users.

Electronic commerce is present in economic life before the proliferation of the Internet. It must be noted that within the e-commerce it has developed mechanisms to that information technology is there to accelerate as it has a strong presence when doing business that is in real time. This means that it can give extremes on the planet since by reducing intermediaries; it has a direct relationship between businesses and consumers. Therefore, transaction costs are reduced and allow entering a global market to offer and demand for goods and services, these characteristics that differentiate the traditional e-commerce.

Porter et al. speaks of the internet architecture, along with other improvements in software architecture and development tools, has become a much more powerful tool for the strategy as these help differentiate companies with presence in e-commerce [15]. If the same products may well have a clear differentiation this can be how the products are offered by web development and offline treatment, which it refers to all sales processes that have to do with the customer after transaction.

To obtain these benefits, however, companies need to stop their rush to adopt generic "out of the box" packaged applications and instead tailor their deployment of Internet technology strategies for their particular applications. Although it remains difficult to customize packaged applications, the inherent difficulty of the task contributes to the sustainability of the resulting competitive advantage. Small businesses have both greater need for resources and an increased risk of appropriation of their own resources and are challenged to compete and collaborate with companies that often have more resources, power and broader social networks [16].

Sales of consumer goods to the general public via the Internet, also known as Retail Internet has generated through e-commerce websites and through pure operated by retailers based store on sales sites. Sales data are attributed to the country where the consumer is based, rather than is attributed where the retailer is based.

\section{Barriers of e-commerce}

According to the UNCTAD it is reviews that there are a number of factors that can restrict commerce, and divided into three groups of economic, socio-political and cognitive barriers [17]. Among the economic obstacles include the inadequacy of ICT infrastructure and its use, lack of reliability and the high cost of electricity supply, the limited use of credit cards, the lack of purchasing power and the low level of development of financial systems.

Among other socio-political obstacles include weak legal and regulatory frameworks, cultural preferences through personal contact and trust of society exclusively in cash. Finally, there are also a number of cognitive obstacles, including low levels of computer literacy and understanding and knowledge of e-commerce, both among consumers and among businesses.

\section{Models E-commerce}

Kumar et al. help to conceptualize ideas, business models as a new organization which speaks of the constancy of the elements that guarantee competition, also involves an investment in the traditional value chain. Definition of customer-focused value, many aspects focus on customer preferences, through highly flexible processes, the client receives the new valuation by the speed of care, personalization and relationship between quality and price [18].

Models on electronic commerce as Tapscott gives the concept of business-web as a business model whose support is the network and which encompass a need to carry out environment. Timmers model that focuses on the value chain the company promoting its products and services and the most tangible consumer benefits are lower prices and greater variety best information convenience. The Timmers model has been widely used for the subjects of "Business web" to measure the relationships between companies and consumers.

Business-to-consumer (B2C) E-commerce: Is best known type of electronic commerce where business presence in online sales reaches consumers. This includes the purchase of goods and services retail products and content online, although according to data of international organizations is relatively small. It has grown exponentially and has extensive international presence by Laudon and Traver [11]. There are seven business models for $\mathrm{B} 2 \mathrm{C}$ such as portals, online stores, content providers, brokers' transaction creators market, service providers and community providers.

Business-to-business (B2B): The model of business to business (B2B) e-commerce is based on transactions made by companies with other companies and it is the model that represents the largest volume of electronic commerce and this poses to Laudon and Traver a size potentially huge [11]. There are two main business models used in the arena: Net B2B Marketplace, including e-distributors, e-procurement, trade and industry consortia and private industrial networks, including networks of individual companies and whole networks the industry.

Helgueros et al. considers the full range of actions that can occur in two organizations, such as purchasing, vendor management, payment management, procurement, and tasks as service and support [19]. This method accounts for $80 \%$ of e-commerce in recent years. Some advantages of this type of electronic commerce are reducing transaction costs and reducing time.

Consumer-to-consumer (C2C): This type of e-commerce consumers speaks of selling to other consumers usually for online sales through auctions as a first consumer electronic market places or using search engines to easily display a catalog of goods or services.

\section{Electronic commerce in Mexico}

E-commerce is changing the economy and how business is done 
these days. It obliges e-commerce companies to find new ways to expand markets where they compete to attract and retain customers by adapting products and services to their needs, and restructure their business processes to deliver products and services more efficiently and effectively. In this section based on data AMIPCI, it will be established how it behaves in Mexico e-commerce in recent years analyzing the number of users, how Mexicans spend in the electronic market and their preferences [20].

Based on data from the AMIPCI in Mexico, it has had significant growth in the number of internet users as shown in Figure 1, of which $37 \%$ have made at least one purchase online at year [20]. Internet users are an important data because they are potential consumers in electronic commerce which have certain barriers to online shopping, such as how access to a computer, internet access, and access to a credit card. Internet users in the event Mexico must remember that as far as Internet providers are subject to a strong oligopoly who's most important is the TELMEX Company.

Internet sales as shown in Figure 2 shows that for the year 2014 amounted to 165.6 billion pesos this represents a $36 \%$ increase over the 2013 and expected in 2015 reach 180 billion pesos, which represents a large increase in relation to the volume of e-commerce to GDP in the last six years for the Mexican economy. It is clear to say that the growth of electronic commerce has but grown significantly. This will be increased in a smaller volume over time because this growth will depend on how much will break the barriers of electronic commerce by businesses and consumers.

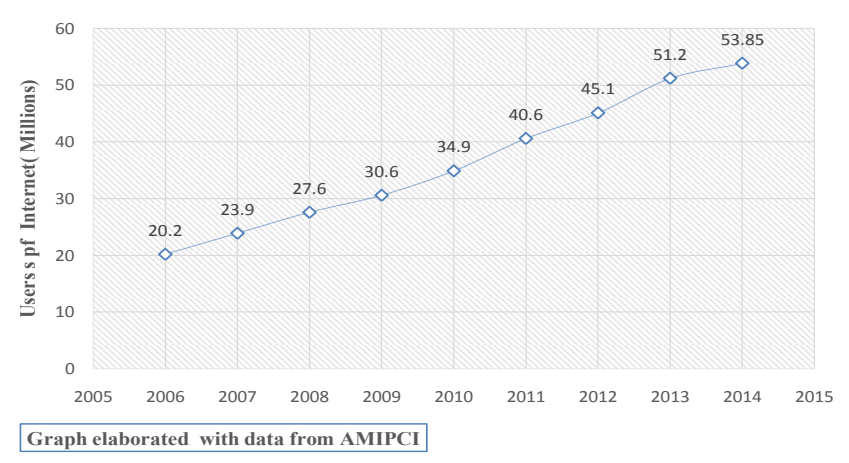

Source: Own elaboration with data of AMIPCI (2014).

Figure 1: Internet users in Mexico.

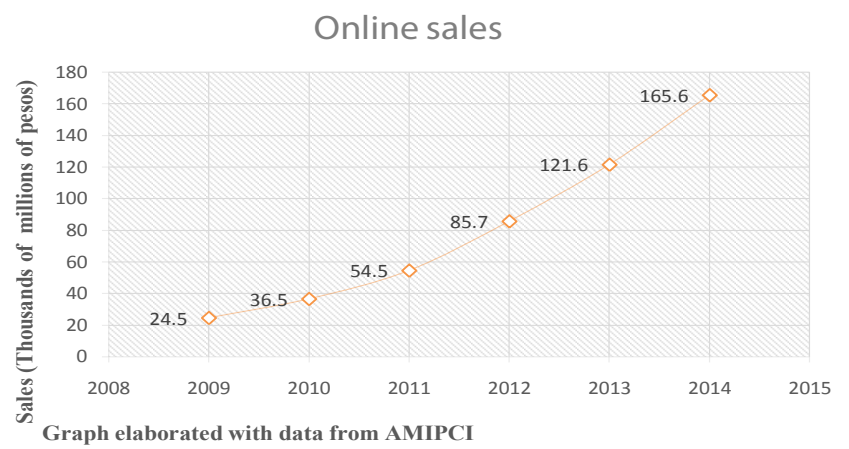

Source: Own elaboration with data from the AMIPCI (2014).

Figure 2: Sales by Internetin Mexico.
Among the most relevant data for electronic commerce must be $97 \%$ of the people who have made purchases online, they would again, so the user experience is positive in recent years. It has increased at constant rate the internet users, as well as Mexico has worked in the legal aspect and regulations in order to provide internet security to Internet users who wish to make purchases, thereby giving credibility to electronic commerce through institutional measures such as quality seal AMIPCI that gives prestige to the companies that own and at the same time gives certainty to the consumer [20] (Figure 2).

New knowledge and skills need to be acquired or developed by companies that enter into e-commerce to successfully enter new electronic markets ranging from cultural differences, the type of institutions which are sought through agreements to regulate cross-border transactions by email to regulate certain aspects of the companies which should work on bringing international rules, and new agents that appear today in e-commerce in the form of intermediaries in electronic commerce markets. The strategic research should be done to have the best decisions around how to enter this electronic market and how to have a presence that may be relevant to SMEs.

Some firms are unwilling to commit the resources to participate in online markets, while others devote their resources to establish the necessary processes to participate in the online business [9]. But today there are more companies that innovate in the field of internet to start making e-commerce while they are still few compared to other countries, Mexico is in a good time to tip its perception of sales to online channels.

The corporate strategy is formulated with the highest administrative levels of the organization and the action plan of a diversified company that covers all levels of its multibusiness model. According to Moreno the strategy should consider several points as seen in industry what its scope will be, to find the most profitable places and see how it uses its resources to expected results and even how it should invest [21]. David states that the implementation of strategies is the implementation of the results obtained in the process of formulating and implementing a plan should know how the business works and there must be motivated staff that shares the vision of the company [22]. I can count at any time adapting to a change in the way of implementation.

Mexican consumers are choosing in higher proportion to make their credit card payments at the few choices they have to do so by branch payments, online payments (PayPal) or in stores, This leads to certain Internet users cannot acquire products online because they do not have a credit card, and this limits them to grow sales at certain points because they should expect an increase in options for payments by companies.

Within Mexican consumers, companies are seeking to adopt strategies as the plus they can offer in terms of promotions, such as from reducing costs implied in the electronic commerce of the base price that the consumer appreciates in the market. Companies can reduce costs and offer some kind of promotion as discounts, free shipping, and months without interests, gifts, rebates, and other. Having companies with online sales or the ability to buy or sell products or services is critical for the advancement of e-commerce, which helped small businesses to be more competitive and thus to be postulated to become traders worldwide.

The role of electronic commerce in the internationalization of enterprises and the use of ICT in the same, in which the information is a pillar of the economy, is the reason why firms investment in technology. Considering the integration of companies in their adoption 
of e-commerce, an important point is the one which seeks to remove certain intermediaries between the company and the consumer, the presence of SMEs in the Internet as marketing and the huge advantage that comes with the firm position of internet users in certain regions (catchment customers) to recognize the advantages achieved by having direct communication with consumers to try to go removing information asymmetries by the pre-sales though the online chats that make sales.

An analysis of production and distribution capacities of companies which are unable to compete in volume with transnational firms, but they can win certain niches in the search of market and leverage its advantages in the process of innovation. These processes must be more authentic as there is no real way for both companies and users who are more demanding on the electronic market. As their cognitive level increases, according to this, information allows to compare and review reputations of sellers (Free market), choose based on what offer Internet suppliers in the same product and gain access to international markets and have more options. Although there are no further developments to diminish both costs for international purchases making more accessible to the consumer, who may have also more options.

\section{Model of Porter's Five Forces}

The forces of Porter are the threat of new entrants, rivalry among existing firms, the threat of substitutes, bargaining power of suppliers, and the bargaining power of buyers [1]. This model applied to electronic commerce can give a great application to electronic commerce. From this can be analyzed some important concepts of electronic commerce using the model as a basis.

- The bargaining power of buyers

- The bargaining power of suppliers

- The threat of new entrants

- The threat of substitute products.

Within the model of Porter luring electronic commerce bargaining power for both suppliers and buyers increases in high volume, because both are destroying some information barriers which allow the consumer or firm to check prices and compare that type of product who want to buy [1]. But, there is within the certain information asymmetries that having a virtual market consumers, do not have the product in their hands and using digital references, they can observe but this does not assure that their expectations and reality is spliced at the moment of receiving their products.

Although opportunism is present, international agencies have started working their rules as institutions seeking that consumers are protected in cross-border transactions and thus avoid being scammed by a salesman who is outside their country. This is to remember that e-commerce breaks geographical barriers to buy in the European Union and which are sent to Latin America. So, these countries must draw certain criteria for trust in internet shopping that does not have a low due to mistrust.

The threat of new entrants is latent because although having an advantage as a sales channel online, competitors do not have major constraint to enter because the entry costs are low in terms of internet presence. But many companies manage to differentiate their sales channels making each time more personalized and investing in information technologies. While moving to electronic level, competitors have minimal barriers to entry if it is very different the investment on web development and infrastructure to send their products to much of the world.

The threat of substitutes is more likely due to the great deal out there in e-commerce. This can foster electronic commerce and consumers to be able to compare prices in real time and also with a single click can be comparing products that seem related. Thus, not only compare prices between brands but also between products that can replace the first choice of consumers. With these volumes of information there are asymmetries of information to compare decrease rapidly.

The rivalry between the actors is more dynamic as consumers may be in the website 24 hours a day as internet breaks the time barriers of purchasing with the option to buy in the hands of the consumer. While competitors may also view on real-time prices of competitors is not as tangible who sells more at first glance, despite the price to the consumer looking for more skills in his suppliers such as delivery times, reputation, quality of service and sales after-sales care.

\section{Conclusions}

Electronic commerce has grown considerably in the way organizations conduct their transactions and global negotiations. Costs for using this technology also are reducing while developing the ability to reach more customers worldwide. It is also included that Mexico still has some issues such as lack of infrastructure to further increase the possibilities of companies to include electronic commerce in their activities.

It is necessary to invest in technology to further exploit electronic commerce and look how it can close the gap between companies in the aspect of development and innovation since although it has grown, electronic commerce could take even more relevance in the coming years since it must take into account that Mexico has a structure with large percentage of companies belonging to SMEs which although not a marked limitation, it should work a little harder to introduce e-commerce.

Some advantages of e-commerce are the speed to purchase products or information; convenience, for example, for the purchase, payment, collection or refund of items, and personalization in each of these interactions [23-25]. Within Mexican consumers, companies are seeking to adopt strategies as the plus they can offer in terms of promotions based on price from reducing costs of electronic commerce that the consumer appreciates. In the market, companies can reduce costs and offer some kind of promotion as discounts, free shipping, months interest, gifts, rebates, other.

Porter's model can be exploited further as the dynamics of certain aspects must remain static for the evaluation and the dynamics of electronic commerce. Sometimes the analysis may not be as useful after certain periods of time and apply to certain industry to be addressed. Since a deficiency of the model is that it can only study the industry and not a specific business. As for the chances of e-commerce behavior positively continue to be a determining factor that companies consider as a strategy to adopt e-commerce and web development platforms and offline logistics system-wide for sales.

\section{References}

1. Porter ME (2008) The five competitive forces that shape strategy. Harvard Businesses Review 86: 25-40.

2. Mata FJ, Fuerst WL, Barney JB (1995) Information technology and sustained competitive advantage: a resource-based analysis. MIS Quarterly 19: 487-505. 
3. Tornatzky LG, Fleischer M (1990) The processes of technological innovation. Lexington Books, Lexington.

4. Rogers EM (1983) Diffusion of innovations. New York: Free Press, London.

5. DiMaggio P, Powell WW (1983) The iron cage revisited: institutional isomorphism and collective rationality in organizational fields. American Sociological Review 48: 147-160.

6. Swanson EB (1994) Information systems innovation among organizations. Management Science 40: 1069-1092.

7. Lancioni RA, Smith MF, Schau HJ (2003) Strategic Internet application trends in supply chain management. Industrial Marketing Management 32: 211-217.

8. Grewal R, Comer JM, Mehta R (2001) An investigation into the antecedents of organizational participation in business-to-business electronic markets. Journal of Marketing 65: 17-33.

9. Sila I (2013) Factors affecting the adoption of B2B e-commerce technologies Electronic commerce research 13: 199-236.

10. Hofstede G (1993) Cultural constraints in management theories. Academy of Management Executive 7: 81-94.

11. Laudon KC, Traver CG (2013) E-commerce. Pearson.

12. Owens J (2006) Electronic business: A business model can make the difference. Management Services 50: 16-24.

13. Figueroa González EG, Hernández Cantú FI, González Herrera MB, Arrieta Díaz D (2013) Commerce as competitive factor in micro, small and medium business sector companies in the state of durango. Revista International Administración and Finanzas 6: 29-44.
14. Renna $P$, Argoneto $P$ (2010) Production planning and automated negotiation for SMEs: An agent based e-procurement application. International Journal of Production Economics 127: 73-84.

15. Porter ME (2001) Strategy and the internet. Harvard business review.

16. Klijn E, Reuer J, Buckley P, Glaister K (2010) Combinations of partners' joint venture formation motives. European Business Review 22: 576-590.

17. UNCTAD (2015) Report on the Information Economy 2015.

18. Kumar R, Raghavan P, Rajagopalan S, Tomkins A (1999). Extracting largescale knowledge bases from the Web. In VLDB 99: 639-650.

19. Helgueros $Y$ (2010) Electronic commerce as a driving strategy of exports in Mexico. International Management \& Finance Magazine 3: 81-90.

20. AMIPCI (2014) Study on electronic commerce in Mexico 2013.

21. Moreno MP (2014) E-commerce and its impact on globalization. Observatory of the Latin American economy.

22. David FR (2003) Strategic management concepts. Prentise hall.

23. González O (2015) Priority to invest in IT in the Retail sector. World Logistics.

24. Mahoney J, Thelen K (2010) A theory of gradual institutional change. Explaining institutional change: Ambiguity, agency, and power. Cambridge University Press.

25. Perez L, Cambra-Fierro J (2015) Value generation in B2B contexts: the SMEs in the State of Durango. Revista International Administración and Finanzas 6: $29-44$. 